\title{
Trauma niewidzialności albo dlaczego literatura ukraińska nie ma Nobla?
}

The trauma of invisibility, or why Ukrainian literature has not won the Nobel prize yet. The allegation that the absence of a Nobel Prize laureate among Ukrainian writers means that Ukrainian literature is underdeveloped is unfair and ignorant. This paper points to the reasons for the invisibility of Ukrainian literature in the world. Academic works in postcolonial studies and polysystem theory prove that literature is never isolated from politic, economic and social environments. Ukrainian literature used to develop in inimical environment; as Russian tsarist and totalitarian authorities oppressed Ukrainian writers, there was no infrastructure that would support Ukrainian literature and promote it abroad. Another issue is Western-centrism of the Swedish Academy. Statistics show that most of the laureates came from the countries of West Europe and the USA. Many times writers from the outlying areas of Europe (Russia, Poland, Greece, Switzerland) were awarded, but the rest of the world is almost invisible for the Nobel Committee. In conclusion, there is a short list of initiatives that are aimed at raising the profile of Ukraine and its culture in the world.

Keywords: postcolonial theory, polysystem theory, Nobel Prize, Ukrainian literature, promotion of culture

Травма невидимости или почему украинская литература не имеет Нобелевской премии. Иногда украинской литературе закидают отсталость, чего доказательством служит отсутствие Нобелевской премии по литературе для украинского писателя. В этой статье изъявим причины невидимости украинской литературы в мире. Пользуясь постколониализмом и теорией полисистемы доказываем, что национальная литература никогда не изольована от политической, экономической и социальной среды. Украинская литература развивалась в неблагоприятной

* Adres do korespondencji: Instytut Filologii Słowiańskiej, ul. Pocztowa 9, 53-313 Wrocław. E-mail: jadwiga.skowron@uwr.edu.pl. Autorka dziękuje za konsultacje panu Radcy Mykole Yarmoliukowi oraz pani Olenie Tsybuch — I Sekretarzowi Ambasady Ukrainy w Warszawie. 
обстановке: русская царская и советская страна преследовала представителей украинской культуры. Известно, не было инфраструктуры, какая поддержала бы украинску литературу и выдвинула бы ее в мире. Другим вопросом становится европоцентризм Шведской академии. Статистики доказывают, что найболее лавреатов со стран Западной Европы и США. Иногда награждались писатели с близкой периферии как Россия, Польша, Греция или Швейцария, однако остальные районы мира почти невидимые для Шведской академии. В заключении статьи названы инициативы намерены исправить имидж Украины в мире и выдвинуть ее культуру.

Ключевые слова: постколониализм, теория полисистемы, Нобелевская премия, украинская литература, маркетинг культуры

Tytułowa „trauma niewidzialności” nie jest terminem psychologicznym, lecz pojęciem ukutym przeze mnie na oznaczenie poczucia straty i krzywdy, powodowanego nieobecnością literatury ukraińskiej w świecie, niedostrzeganiem i niedocenianiem tej literatury. Opisane poczucie krzywdy, a przede wszystkim jego istotny komponent, jakim jest brak Nagrody Nobla, stanowi przedmiot badań zaprezentowanych w niniejszym artykule. Hasło „trauma” nawiązuje do tytułu konferencji „Trauma jako kulturowy palimpsest: (post)komunizm w kontekście porównawczym nowoczesności, totalitaryzmów i (post)kolonializmów", na której wygłosiłam wstępne tezy poniższego tekstu. Pytanie „dlaczego literatura ukraińska nie ma Nobla?”, postawione w drugiej części tytułu, stanowi problem badawczy niniejszego wywodu, a celem rozważań jest znalezienie odpowiedzi na pytania: Czy brak literackiej Nagrody Nobla dla Ukrainy wynika z niskiego poziomu artystycznego literatury ukraińskiej? Czy istnieją pozaestetyczne przyczyny braku literackiej Nagrody Nobla dla twórcy pochodzącego z Ukrainy?

Brak Nagrody Nobla jest stałym elementem dyskursu krytyczno-literackiego na Ukrainie. Poświęcono tej kwestii wiele artykułów, a o „kompleksie Nobla” wspomina Wołodymyr Danyłenko w książce o charakterze publicystycznym, zatytułowanej Лiсоруб у пустелі. Письменник і літературний процес. Począwszy od $1915 \mathrm{roku}$, raz po raz podejmowane są starania o Nagrodę Nobla dla pisarza ukraińskiego - jak dotąd bez powodzenia. W listopadzie 1915 roku kandydaturę Iwana Franki zgłosił wiedeński profesor Josyp Zastyreć ${ }^{1}$, jednakże w owym czasie lista propozycji do nagrody za 1916 rok była już zamknięta. Niestety w tymże roku Iwan Franko zmarł, co uniemożliwiło zgłoszenie jego kandydatury w roku kolejnym ${ }^{2}$. W 1963 roku emigracyjne środowiska ukraińskie zmobilizowały się w celu wsparcia kandydatury Iwana Bahrianego. Listy do Akademii Szwedzkiej słali: Ukraińska Wolna Akademia Nauk w USA, australijski oddział Towarzystwa Naukowego im. Szewczenki i organizacja pisarzy ukraińskich „Słowo”. Przekłady powieści Тигролови zostały w tamtym czasie opublikowane w Kanadzie, USA, Niemczech i Holandii. Znów na przeszkodzie

${ }^{1}$ П. Бубній, Іван Франко: екскурс в нобеліану, «Збірник праць ТО НТШ», t. 5. Нобелівський рух і Україна, Тернопіль 2010, s. 148-149.

2 П. Антоненко, Нобелівські лабіринти України, „Сіверщина” 25.11.2010, http://siver.com. ua/publ/nobelivski_labirinti_ukrajini/4-1-0-226 (dostęp: 7.01.2017). 
stanęła śmierć kandydata - Iwan Bahrianyj zmarł w Niemczech 25 sierpnia 1963 roku. W 1980 roku zgłoszono kandydaturę Ułasia Samczuka za trylogię Wołyń. Nie został jednak nagrodzony. Omelian Pricak, profesor Harvardu, historyk i orientalista, dwukrotnie zgłaszał ukraińskich kandydatów: Pawła Tyczynę w 1966 roku i Mykołę Bażana w 1970 roku. W odróżnieniu od Bahrianego i Samczuka, byli to twórcy legalnie publikujący w USRR, co stawiało ich kandydatury w gorszym świetle, gdyż świat zachodni wspierał zazwyczaj antykomunistycznych dysydentów. Bażan, jak zaznacza Petro Antonenko ${ }^{3}$, wysłał list do Akademii Szwedzkiej, w którym sprzeciwił się nominowaniu jego osoby do Nagrody Nobla.

Wachtang Kipiani zbadał historię starań o nominację Wasyla Stusa ${ }^{4}$. W celu zweryfikowania mitów związanych ze wspomnianą nominacją dziennikarz przeszukał archiwum „Smołoskypu”. Danyłenko stwierdza, że ogłoszenie nominacji Stusa do Nagrody Nobla skróciło życie poety uwięzionego w łagrach. Jedna z najbardziej rozpowszechnionych wersji wydarzeń zawiera informację, że decyzja o przyznaniu nagrody Stusowi zapadła, ale śmierć poety przekreśliła oficjalne ogłoszenie werdyktu. Kipiani dociera jednak do informacji, że do rozpatrzenia kandydatury autora tomu Зимові дерева w ogóle nie doszło. W gazecie „Ameryka” z 17 grudnia 1985 roku dziennikarz znajduje wzmiankę o „Międzynarodowym Komitecie na Rzecz Przyznania Nagrody Nobla Wasylowi Stusowi w 1986 roku", założonym w Toronto pod koniec 1984 roku, nie zachowały się jednak ślady szczególnie aktywnej działalności komitetu. Dziennikarz bada też kwestię inicjatywy niemieckiego noblisty literackiego Heinricha Bölla, który według przekazów miał zgłosić kandydaturę Stusa, jednak w archiwach nie zachowało się nic poza wypowiedziami niemieckiego pisarza, w których domagał się zwolnienia poety z łagru. Kipiani zauważa, że w tamtym czasie było bardzo mało przekładów Stusa na język angielski. Komitet założony w Toronto zebrał datki na publikację, a efektem tych starań było wydanie Selected poems - zbioru 46 wierszy wybranych z tomów Зимові дерева і Свіча в свічаді w przekładzie Jaropełka Lisowskiego. Książka ukazała się w monachijskim wydawnictwie „Сучасність” w 1986 roku, więc nie było już sensu wysyłać jej do Sztokholmu. Jak odnotowuje Kipiani, nie były to zresztą pełnowartościowe przekłady poezji, tylko - na co wskazał sam tłumacz - synoptic translation, a i niszowe wydawnictwo nie sprzyjało promocji twórczości Stusa w szerokim kręgu europejskich czytelników.

Przytoczona historia starań o literackiego Nobla dla pisarza z Ukrainy pokazuje, że w krajach zachodnich literatura ukraińska jest właściwie nieznana. Jeśli członkowie Akademii Szwedzkiej i inni potencjalni czytelnicy nie mają dostępu do utworów pisarzy ukraińskich za pośrednictwem tłumaczeń, nie są w stanie ocenić ich wartości estetycznej. Niewidzialność literatury ukraińskiej w świecie świadczy o jej pozycji peryferyjnej w stosunku do literatur centralnych. W zestawieniu 50 języków oryginalnych, z których dokonuje się na świecie najwięcej przekładów, na

${ }^{3}$ Ibidem.

4 В. Кіпіані, Стус і Нобель. Демістибікація міфу, „Українська Правда” 22.07.2006, http:// www.pravda.com.ua/articles/2006/07/22/3133311/ (dostęp: 7.01.2017). 
szczycie listy widnieją kolejno język angielski, francuski i niemiecki, czwartą pozycję zaś zajmuje język rosyjski ${ }^{5}$. Dla porównania język polski znajduje się na czternastej pozycji, a ukraiński - trzydziestej szóstej. Zarysowująca się we wspomnianym zestawieniu mapa literatur świata $\mathrm{z}$ podziałem na literatury centralne, będące literaturami narodowymi imperiów, i literatury peryferyjne, które są literaturami narodowymi w państwach o mniejszym znaczeniu politycznym i gospodarczym, skłania do umiejscowienia przedmiotu prezentowanych badań w kręgu studiów postkolonialnych oraz teorii polisystemów. Perspektywa postkolonialna jest obecnie chętnie stosowana w badaniu literatury ukraińskiej, korzystają z niej m.in. Tamara Hundorowa $^{6}$, Marko Pawłyszyn ${ }^{7}$, Myrosław Szkandrij ${ }^{8}$, Hryhorij Hrabowycz (George G. Grabowicz $)^{9}$, Ola Hnatiuk ${ }^{10}$, Bogusław Bakuła ${ }^{11}$ i Agnieszka Matusiak ${ }^{12}$. Należy również wspomnieć o publicystyce Mykoły Riabczuka ${ }^{13}$, który w kluczu postkolonialnym analizuje zjawiska zachodzące w społeczeństwie ukraińskim.

Rolę przekładu literackiego w kontekście literatur narodowych rozumianych jako polisystemy badał Itamar Even-Zohar ${ }^{14}$, wskazując na odmienności między literaturami centralnymi a peryferyjnymi. Even-Zohar wykazał, że literatury narodowe, których proces rozwoju przebiegał $\mathrm{w}$ niesprzyjających warunkach politycznych, zajmują pozycje peryferyjne w stosunku do literatur narodowych rozwijających się w dobrze prosperujących państwach:

Na półkuli zachodniej literatury peryferyjne bardzo często są tożsame z literaturami mniejszych narodów, zatem, mimo iż koncepcja ta może się wydać niestrawna, musimy przyjąć, że wewnątrz powiązanej relacjami grupy literatur narodowych — na przykład w grupie literatur europejskich — relacje hierarchiczne zostały ustalone od samego początku ${ }^{15}$.

${ }^{5}$ Index Translationum: UNESCO Culture Sector, http://www.unesco.org/xtrans/bsstatexp. aspx? crit1L=3\&nTyp=min\&topN=50 (dostęp: 18.01.2017).

6 Т. Гундорова, Післячорнобильська бібліотека. Український літературний постмодерн, Київ 2005; еадет, Транзитна культура. Симптоми постколоніальної травми, Київ 2013.

${ }^{7}$ М. Павлишин, Канон та іконостас, Київ 1997.

${ }^{8}$ М. Шкандрій, В обіймах імперії. Російська і украӥнська літератури новітньої доби, Київ 2004.

9 Г. Грабович, На теоретичному риштованні, [w:] idem, До історії української літератури, Київ 2003, s. 17-126.

10 O. Hnatiuk, Pożegnanie z imperium. Ukraińskie dyskusje o tożsamości, Lublin 2003.

11 B. Bakuła, Europa Środkowo-Wschodnia i jej (post)kolonialny świat i Studia postkolonialne w Europie Środkowej oraz Wschodniej. Kwerenda wybranych problemów (1991-2014), [w:] Dyskurs postkolonialny we współczesnej literaturze i kulturze Europy Środkowo-Wschodniej, red. B. Bakuła, Poznań 2015, s. 13-181.

12 Постколоніалізм - Генерації - Культура. Теоретичні Ревізї, випуск 4, наук. ред. А. Матусяк, Т. Гундорова, Київ 2014.

${ }^{13}$ M. Riabczuk, Od Małorosji do Ukrainy, tłum. O. Hnatiuk, K. Kotyńska, Kraków 2002; M. Riabczuk, Ukraina: syndrom postkolonialny, tłum. zbiorowe, Wrocław-Wojnowice 2015.

${ }^{14}$ I. Even-Zohar, Miejsce literatury tłumaczonej w polisystemie literackim, [w:] Wspótczesne teorie przekładu. Antologia, red. P. Bukowski, M. Heydel, Kraków 2009, s. 197-203.

${ }^{15}$ Ibidem, s. 200. 
Punktem wyjścia dla izraelskiego badacza były badania literatury nowo powstałego po II wojnie światowej państwa Izrael. Choć historia Izraela i historia Ukrainy istotnie się różnią, można odnaleźć pewne analogie między historią literatury hebrajskiej a historią literatury ukraińskiej i zauważyć, że brak państwowości utrudniał rozwój obu literatur, skazując je na pozycję peryferyjną w makropolisystemie literatur europejskich. Według przytaczanych wyżej danych statystycznych Index Translationum, wskazujących 50 języków, z których dokonuje się najwięcej przekładów, literatura hebrajska zajmuje pozycję dwudziestą. Warto dodać, że w pierwszej 20 rankingu zdecydowaną większość stanowią języki europejskie, a jedyne języki spoza Europy to japoński (pozycja ósma), chiński (szesnasta) i arabski (siedemnasta). Można zatem stwierdzić, iż statystyka ta ilustruje postkolonialny krajobraz kulturowy globu. Itamar Even-Zohar zauważył, że w systemach literatur centralnych przekłady z innych języków nie odgrywają tak istotnej roli, jak w systemach literatur peryferyjnych. Dla niniejszych rozważań oznacza to, że o ile przekłady z innych literatur odgrywają ważną rolę w polisystemie literatury ukraińskiej, o tyle przekłady z literatury ukraińskiej nie mają większego znaczenia dla polisystemów literatur centralnych. Znaczenie teorii polisystemów dla badań przekładu w powiązaniu z teorią postkolonialną podkreśla także Douglas Robinson w pracy Translation and Empire ${ }^{16}$.

Z nurtem studiów polisystemowych związany był również André Lefevere ${ }^{17}$, który rozwinął tę koncepcję i wyszczególnił elementy systemu literatury, takie jak patronat, kod postępowania (czyli poetyka oraz pogląd na to, jak literatura powinna funkcjonować w społeczeństwie) i język naturalny, w którym powstają poszczególne dzieła literackie ${ }^{18}$. Patronat rozumiany jest przez badacza jako władza państwa, w którym rozwija się dana literatura narodowa - obecnie są to powoływane przez rządy instytucje mające wspierać i promować kulturę, a także rozdysponowywać środki finansowe przeznaczone na ten cel. W państwie demokratycznym mamy do czynienia z patronatem niejednorodnym, gdy obok siebie funkcjonują różne czasopisma, środowiska, nagrody literackie itd. Z kolei w państwie totalitarnym, w którym władza legalizuje tylko jedną ideologię, patronat ma charakter jednorodny i podporządkowuje sobie wszystkie elementy systemu literatury. Zarówno w warunkach caratu Imperium Rosyjskiego, jak i w Związku Radzieckim literatura ukraińska podporządkowana była patronatowi jednorodnemu, który preferował inną literaturę narodową - rosyjską. Sprawowanie patronatu przez partię komunistyczną, jak wiadomo, wiązało się z narzucaniem preferowanej metody twórczej (socrealizmu), surową cenzurą i stosowaniem represji wobec autorów niepokornych - represji równoznacznych niekiedy z wyrokiem śmierci. Literaturze ukraińskiej uniemożliwiono zatem wszechstronny rozwój i odizolowano ją od świata, co utrwaliło jej peryferyjny status. O owej „traumie upośledzenia” poszczególnych elementów systemu literatury, takich jak autor, repertuar tematyczny, stylistyczny i gatunkowy,

\footnotetext{
16 D. Robinson, Translation and Empire, Manchester 1997, s. 12.

17 A. Lefevere, Ogórki Matki Courage, [w:] Współczesne teorie przekładu..., s. 224-246.

18 Ibidem, s. 228-230.
} 
pisze Hryhorij Hrabowycz we wstępie do zbioru swoich esejów, artykułów i badań До історії украӥнської літератури ${ }^{19}$. Literaturoznawca podkreśla też wagę self-image $e^{20}$, czyli samooceny uczestników ukraińskiego procesu literackiego, mogących przyjąć i uwewnętrznić narzucone przez kolonizatora przekonanie o niższości kultury, której są reprezentantami. Ślady internalizacji takiego poglądu dostrzegam m.in. w podsumowaniu opublikowanej na łamach czasopisma „Сучасність” w 1986 roku analizy przekładu wiersza Czesława Miłosza Który skrzywdziłeś na język ukraiński, w którym krytyk Bohdan Strumiński stwierdza, że przywiązanie do tradycji natywistyczno-folklorystyczno-magiczno-sentymentalnej świadczy o zacofaniu poezji ukraińskiej. Strumiński wyraża przekonanie o ułomności ukraińskiej tradycji literackiej i wysuwa tezę, że właśnie z tego powodu literatura ta nie otrzymała Nagrody Nobla $^{21}$. Przypominam, że tradycja literacka rozumiana jako komponent repertuarowy poetyki jest według Lefevere’a jednym z elementów systemu literatury. Innym wymienionym przez badacza elementem tegoż systemu jest język naturalny, w którym tworzona jest dana literatura narodowa. Do dziś (co zaraz udowodnię) można usłyszeć echo słów czołowego rosyjskiego krytyka z połowy XIX wieku, Wissariona Bielińskiego, który w reakcji na twórczość Tarasa Szewczenki sformułował następujące zdanie:

Szkoda by było, gdyby malutki dar talentu stracił swoje siły, pisząc po małorosyjsku — dla małorosyjskich wieśniaków... Zaprawdę piękna to literatura oddychająca jedynie prostactwem wiejskiego języka i tępotą chłopskiego umysłu! 22

Rosyjski krytyk, wypowiadając się w duchu carskiego imperializmu, nie uznawał odrębności języka ukraińskiego, albowiem określenie „małorosyjski” oznacza regionalność, peryferyjność wobec uważanego za nadrzędny języka rosyjskiego. Bieliński zaprzecza też istnieniu kolejnego elementu systemu literatury, jakim jest odbiorca. Brak kompetentnych czytelników ma, zdaniem krytyka, przesądzić o bezcelowości tworzenia literatury w dialekcie, którego jedynymi użytkownikami są prości chłopi. W formułowanych współcześnie wypowiedziach zawierających twierdzenie, iż język ukraiński nie jest wystarczająco sprawny czy bogaty, aby stanowić budulec wartościowych dzieł literackich, dostrzegam echo cytowanych powyżej słów dziewiętnastowiecznego rosyjskiego krytyka. Przekonanie o tym, że na obszarze dawnego ZSRR jedynie język rosyjski pozwala pisarzowi w pełni zrealizować ambitny zamysł twórczy, zauważyłam w wypowiedzi tłumaczki Walentyny Mikołajczyk-Trzcińskiej, nawiązującej do twórczości ukraińskiego dramaturga, Anatolija Krymskiego, piszą-

${ }^{19}$ Г. Грабович, До історії..., s. 11.

${ }^{20}$ Ibidem.

21 Б. Струмінський, Мої клопоти з певною традицією в украӥнській тітературі, „Сучасність” 1986, nr 4, s. 116.

22 W. Bielinskij, „Istorija malorossii” Nikolaja Markewycza, [w:] Polnoje sobranije soczinienij w $13 \mathrm{t}$., t. 7, Moskwa 1955 [1843], s. 60-63, cyt. za: M. Riabczuk, Ukraina. Syndrom..., s. 79. 
cego w języku rosyjskim. W wywiadzie dla czasopisma „Sprawy Nauki” tłumaczka stwierdza:

Pisanie w języku rosyjskim to w ogóle ciekawy temat. Myślę, że jeszcze wiele lat dojrzali pisarze z dawnego obszaru ZSRR będą pisać po rosyjsku i będą tłumaczeni na swoje języki narodowe. [...] Jakie są tego powody? Raz, że w wielu przypadkach przez dziesiątki lat - a w niektórych przypadkach i dłużej — język rosyjski był językiem urzędowym, wykładowym na uczelniach, językiem literatury i elit, a dwa - żejęzyki narodowe z tegoż powodu są nazbyt ubogie, by w nich swobodnie tworzyćc 23 [wyr. - J.S.].

Literatura ukraińska rzeczywiście jest dwujęzyczna, obok autorów ukraińskojęzycznych tworzą pisarze rosyjskojęzyczni (np. Andrij Kurkow, Wołodymyr Rafiejenko), których książki są tłumaczone na język ukraiński. Na język rosyjski tłumaczone są z kolei utwory niewątpliwie dojrzałych pisarzy, jakimi są Oksana Zabużko, Jurij Andruchowycz czy Serhij Żadan. Pragnę zauważyć, że tłumaczenie z języka kultury skolonizowanej na język kolonizatora odgrywa ważną rolę w procesie dekolonizacji ${ }^{24}$.

Troje wymienionych autorów zostało laureatami Literackiej Nagrody Europy Środkowej „Angelus” ufundowanej przez miasto Wrocław, co świadczy o tym, że tworzą literaturę bardzo dobrej jakości i cieszą się międzynarodowym uznaniem. Być może w przyszłości nazwisko jednej z tych osób zostanie ogłoszone w werdykcie komitetu Nagrody Nobla w dziedzinie literatury.

Poświęcę teraz nieco uwagi odznaczeniu, które stanowi wymarzone uwieńczenie kariery i potwierdzenie wybitności twórcy literatury. W monografii Nagroda Nobla jako symbol globalnych norm i idei społecznych czytamy o kontrowersjach wokół prestiżowego odznaczenia. Fundator w swoim testamencie pozostawił zapis, że nagrodę w dziedzinie literatury należy przyznawać za dzieło wybitne i idealistyczne, a, jak czytamy we wspomnianej monografii, „splata się w tym idealizmie najpewniej kilka elementów ważnych dla jego [Nobla] poglądów — oświeceniowa, romantyczna i rewolucyjna tradycja" 25 . Zadanie wyboru laureatów Nobel powierzył Akademii Szwedzkiej, instytucji wówczas bardzo konserwatywnej, jak zauważa Elżbieta Stadtmüller (autorka interesującego nas rozdziału we wspomnianej monografii), rozumiejącej pojęcie „idealizmu” inaczej niż fundator ${ }^{26}$, instytucji, która przeważnie sta-

${ }^{23}$ Tłumaczę to, co wartościowe. Z Walentyna Mikołajczyk-Trzcińska, tłumaczka prozy rosyjskiej rozmawia Leszek Bereśnicki, „Sprawy Nauki” 29.07.2011, http://www.sprawynauki.edu.pl/index. php?option=com_content\&view=article\&id=1906\&catid=316\&Itemid=27 (dostęp: 7.01 .2017$)$.

${ }^{24} \mathrm{O}$ roli tłumaczenia utworów literackich z języka kultury skolonizowanej na język kolonizatora w procesie dekolonizacji wspomina Douglas Robinson w pracy Translation and Empire; D. Robinson, op. cit., s. 31.

${ }^{25}$ M. Głowacka et al., Nagroda Nobla jako symbol globalnych norm i idei społecznych, Wrocław 2016, s. 59.

${ }^{26}$ Ibidem, s. 60. 
rała się omijać twórców o radykalnych poglądach politycznych, aby nie bulwersować opinii publicznej ${ }^{27}$ :

W efekcie wiele wskazań laureatów byłoby szokiem dla Nobla. Ze światowością nagrody też borykano się długo, [...] widać nawet nadreprezentację nie tylko europejsko-amerykańskiej hemisfery, ale i Skandynawii (14 autorów nagrodzonych w XX w.). Dopiero od lat 70. nastąpiło przeorientowanie na osiągnięcia, które nie są „powszechnie dostrzegane”, co wprowadziło do grona noblistów przedstawicieli innych kultur i kontynentów. Temu też trudno się dziwić, przecież kolonializm jako system przetrwał w Afryce do lat 60.-70., a jego upadek wcale nie oznaczał natychmiastowego przełamania uprzedzeń rasowych i kulturowych. Europocentryzm nadal królował w myśleniu, tym razem nie w kategorii planowania politycznego, ale w trwającym przekonaniu, że najlepsze recepty na rozwój i najwyższa jakość kultury pochodzi z „cywilizacji atlantyckiej”, czyli byłych metropolii kolonialnych oraz Stanów Zjednoczonych ${ }^{28}$.

Nieco dalej badaczka przytacza opinię Parka Buckera, który zarzuca Akademii wiele pomyłek, a także wskazuje na stojące za werdyktami przyczyny personalne i ideologiczne. Przykładem tych ostatnich jest „wahnięcie od europocentryzmu i konserwatyzmu do coraz częstszych wyborów nie ze względu na wartość artystyczną, lecz na kalkulacje, któremu »krajowi, płci, pochodzeniu « trzeba by przyznać nagrodę"29. Stadtmüller przywołuje też argumenty Richarda Wiresa, dostrzegającego mianowicie, iż decyzje komitetu należy analizować z uwzględnieniem kontekstu historycznego, ze świadomością, że za konkretnym wyborem stała określona polityka, sama literatura zaś ewoluowała „w swej treści, przesłaniu, jak i konwencji artystycznej”, zmieniały się także „gusty i oczekiwania co do roli, jaką ma odgrywać"30. Uwidacznia się tu podejście bliskie wspomnianej teorii systemów, badającej proces literacki w szerokim kontekście politycznym, ekonomicznym i społecznym.

W zestawieniu liczby noblistów w kategorii literatury z poszczególnych literatur narodowych dane liczbowe potwierdzają nadreprezentację autorów kręgu euroatlantyckiego $\mathrm{w}$ werdyktach nagrody uważanej za globalną. Krajem z najwyższą liczbą literackich noblistów jest Francja (16), drugie miejsce zajmują Stany Zjednoczone (11), na trzecim jest Wielka Brytania (10), dalej ex equo Niemcy i Szwecja (8), następnie Włochy (6) i Hiszpania (6), Polska (5), Irlandia (4), Rosja/ZSRR (4), Dania (3), Norwegia (3), Chiny (2), Japonia (2), RPA (2), Grecja (2), Chile (2), Szwajcaria (2). Jednym laureatem Nagrody Nobla w dziedzinie literatury mogą poszczycić się Belgia, Indie, Finlandia, Islandia, Jugosławia, Izrael, Turcja, Gwatemala, Australia, Bułgaria, Kolumbia, Czechosłowacja, Nigeria, Egipt, Meksyk, Saint Lucia, Portugalia, Węgry, Austria, Mauritius, Peru, Kanada i Białoruś. Pierwsze pozycje zajmują pań-

${ }^{27}$ Ibidem, s. 75.

${ }^{28}$ Ibidem, s. 60.

29 P. Bucker, Introduction, [w:] Dictionary of Literary Biography, t. 329. Nobel Prize Laureates in Literature, part 1. Agnon-Eucken, Detroit 2007, s. XVIII-XIX; cyt. za: Nagroda Nobla jako symbol..., s. 76.

${ }^{30}$ R. Wires, The Politics of the Nobel Prize in Literature. A Study of Criteria behind the Choice. How Laureates Were Selected (1901-2007), New York 2008; cyt. za: Nagroda Nobla jako symbol..., s. 76. 
stwa o mocnych gospodarkach, przeważnie z imperialną przeszłością, „przodownicy” zachodniej cywilizacji. Polska, choć w czasie ustanowienia Nagrody Nobla nie miała własnej państwowości, to jednak mogła poszczycić się tym, że w przeszłości była lokalnym imperium, nie bez znaczenia jest także jej położenie geograficzne - sąsiedztwo ze Szwecją. Cały kontynent azjatycki ma łącznie 7 laureatów, afrykański - 5, a Ameryka Południowa i Środkowa - 6. Dane liczbowe wykazują europocentryzm Nagrody Nobla. Pisarze z krajów pozaeuropejskich otrzymali Nagrodę Nobla łącznie 18 razy, zaledwie o dwa razy więcej niż Francja.

Kolejnych danych dostarczy nam zestawienie liczby języków, w których tworzyli poszczególni laureaci ${ }^{31}$. Tu na pierwszym miejscu znajduje się język angielski (28), następnie francuski (14), niemiecki (13), hiszpański (11), szwedzki (7), włoski (6), rosyjski (6), polski (4) ${ }^{32}$, duński (3), norweski (3), chiński (2), grecki (2), japoński (2), arabski (1), bengalski (1), czeski (1), fiński (1), hebrajski (1), węgierski (1), islandzki (1), prowansalski (1), portugalski (1), serbsko-chorwacki (1), turecki (1), jidysz (1). Niektórzy laureaci byli wielojęzyczni, ale zostali w zestawieniu przyporządkowani do jednego języka, np. Josip Brodski, który, choć tworzył w języku rosyjskim i angielskim, został uznany za autora rosyjskojęzycznego. Jak widać, Nagrodą Nobla odznaczono zaledwie 9 pisarzy tworzących w językach nieeuropejskich w stosunku do 104 pisarzy tworzących w językach europejskich.

Jako jeden z najliczniejszych narodów europejskich, Ukraińcy czują się boleśnie pominięci przez Akademię Szwedzką, uosabiającą niejako zachodnią cywilizację, gdyż, jak pisze Danyłenko, „Nagroda Nobla w dziedzinie literatury jest miernikiem duchowej dojrzałości narodu”33, a jej brak potwierdza, że „Ukraina nie jest zintegrowana z ogólnoświatową przestrzenią kulturalną"34. Niewielką jedynie pociechą jest ukraińskie pochodzenie matki Borysa Pasternaka czy buczackie korzenie Samuela Agnona. Izraelski noblista, urodzony w Buczaczu, opisywał w swoich utworach życie galicyjskich Żydów, początkowo tworzył w jidysz, a po przeniesieniu się do Palestyny - w języku hebrajskim. W Buczaczu powstała organizacja jego imienia - Centrum Literackie imienia Agnona ${ }^{35}$, której głównym celem jest przywrócenie literackiej tożsamości miasta Buczacza.

Wskazałam już, że tytułowa niewidzialność wynika ze znikomej liczby tłumaczeń literatury ukraińskiej na języki zachodnie. To przekonanie potwierdzają dane zgromadzone $\mathrm{w}$ cytowanej bazie Index Translationum ${ }^{36}$ prowadzonej przez UNESCO. Dane te nie są niestety aktualizowane każdego roku, jednak mogą w przybliże-

${ }^{31}$ Nobelprize.org, The Official Web Site of Nobel Prize, Facts on the Nobel Prize in Literature, http://www.nobelprize.org/nobel_prizes/facts/literature/index.html (dostęp: 18.01.2017).

${ }^{32}$ Izaak Bashevis Singer tworzył w jidysz, jednak został ujęty w zestawieniu jako polski autor ze względu na geograficzne umiejscowienie akcji jego utworów.

${ }^{33}$ В. Даниленко, Лісоруб у пустелі. Письменник і літературний проиес, Київ 2008,

34 Ibidem, s. 63.

${ }^{35}$ Nazwa organizacji w języku ukraińskim brzmi „Літературний центр імені Агнона”.

${ }^{36}$ Index Translationum: UNESCO Culture Sector, http://portal.unesco.org/culture/en/ev.phpURL_ID=7810\&URL_DO=DO_TOPIC\&URL_SECTION=201.html (dostęp: 18.01.2017). 
niu pokazać sytuację języka ukraińskiego w ogólnym planie tłumaczeń na świecie. Przykładowo w zestawieniu Top50, 50 języków, z których tłumaczy się najwięcej, ukraiński plasuje się na pozycji nr 36, a w zestawieniu 50 języków, na które dokonuje się najwięcej przekładów - na miejscu nr 39. Index Translationum pozwala nam sprawdzić, w jakich 10 krajach dokonuje się najwięcej tłumaczeń $\mathrm{z}$ danego języka. I tak z ukraińskiego najwięcej tłumaczyło się w USRR - 1993 pozycje książkowe (dane zgromadzone do $1991 \mathrm{roku}$ ), następnie w Polsce - 105 pozycji (nie podano, o jaki okres chodzi, ale $\mathrm{z}$ własnych badań ${ }^{37}$ wiemy, że w przybliżeniu taka liczba publikacji ukazała się tylko w latach 1989-2015), Czechosłowacji - 94 (dane pochodzą z okresu do 1992 roku), Niemczech - 94, Federacji Rosyjskiej - 79, Kanadzie - 76, Bułgarii - 60, na Ukrainie - 58 (dane z okresu 1991-2003), w USA — 55 i w NRD - 41 (do 1990 roku). Doskonale widać, że książki ukraińskich autorów tłumaczono przede wszystkim w krajach bloku wschodniego. Jeśli chodzi o dostępność literatury ukraińskiej w przekładach na języki znane członkom komitetu przyznającego Nagrodę Nobla, liczba pozycji jest znikoma. Należy zauważyć, że oprócz fizycznego ukazania się danej pozycji książkowej znaczenie ma również promocja: wywiady $\mathrm{z}$ pisarzem $\mathrm{w}$ mediach, spotkania autorskie, udział autora $\mathrm{w}$ festiwalach literackich oraz autorytet ojczyzny autora w kraju, w którym wydano przekład.

Nadzieję na lepszą przyszłość dają inicjatywy, jakie pojawiły się w ostatnich latach. Założona w 2007 roku przez biznesmenów Arsenija Jaceniuka i Zbigniewa Drzymałę fundacja „Open Ukraine” ma na celu budowanie autorytetu Ukrainy w świecie. W sferze kultury prowadziła do 2014 roku dwa programy grantowe: Fundusz Książkowy, finansujący przekłady literatury ukraińskiej na języki europejskie, oraz Granty Podróżne dla ukraińskich artystów chcących wyjechać za granicę w celu rozwijania warsztatu, udziału w konkursach lub promowania swojej sztuki. Fundacja zasponsorowała też dwukrotnie stoisko Ukrainy na międzynarodowych targach książki w Paryżu (2013 i 2014). Od roku 2015 wspomniane programy zostały tymczasowo zawieszone.

Od 2004 roku działa w Paryżu Ukraińskie Centrum Kulturalno-Informacyjne przy Ambasadzie Ukrainy we Francji. Sekretarzem ds. kultury przy wspomnianej Ambasadzie jest od jesieni 2015 roku znana ukraińska artystka - Irena Karpa. Jednym z jej priorytetów stało się usprawnienie działalności Centrum, które ma za zadanie budowanie pozytywnego wizerunku Ukrainy jako państwa europejskiego, mającego bogatą kulturę i historię, atrakcyjnego partnera w sferze gospodarczej, naukowej, oświatowej i turystycznej.

Na Ukrainie trwa dyskusja o potrzebie stworzenia sieci Instytutów Ukraińskich. Na stronie Ministerstwa Kultury Ukrainy ostatnia informacja o projekcie ustawy założycielskiej Instytutu Ukraińskiego została zamieszczona w kwietniu 2016 roku. W pierwszym paragrafie czytamy, że Instytut Ukraiński zostaje powołany w celu

${ }^{37}$ Rozprawa doktorska Recepcja najnowszej literatury ukraińskiej w przekładach na język polski po roku 1989. Wybrane zagadnienia w ujęciu diachronicznym i synchronicznym, Wrocław 2015 (książka w przygotowaniu). 
formowania pozytywnego wizerunku Ukrainy w świecie, ma funkcjonować w sferze kultury i sztuki, ochrony dziedzictwa kulturowego, polityki językowej, kinematografii, oświaty, nauki, wymiany kulturalnej i innych. W momencie oddawania niniejszego tekstu do druku ustawa nadal znajdowała się w fazie projektu.

Za to w Sztokholmie - czyli w noblowskim epicentrum - w 2014 roku rozpoczął działalność Instytut Ukraiński, będący inicjatywą obywatelską o charakterze non-profit, niepodlegającą Ministerstwu Kultury Ukrainy. Organizacja zajmuje się promocją kultury ukraińskiej w Szwecji z wykorzystaniem najnowocześniejszych metod. Jeśli chodzi o ukraińskie nadzieje na Nagrodę Nobla, to właśnie ta inicjatywa zdaje się mieć najwyższy potencjał skuteczności.

Odpowiadając na pytania postawione we wstępie, stwierdzam, że nie niski poziom artystyczny literatury ukraińskiej i nie brak talentu pisarzy ukraińskich zadecydował o nieprzyznaniu żadnemu z nich Nagrody Nobla. Przyczyną niewidzialności literatury ukraińskiej w przestrzeni ogólnoświatowej jest brak infrastruktury wynikający z kolonialnej i totalitarnej przemocy, której doświadczał naród ukraiński na przestrzeni stuleci. Także po uzyskaniu przez Ukrainę niepodległości zabrakło mecenatu państwowego, który wspierałby rozwój literatury ukraińskiej wewnątrz kraju i jej promocję w świecie.

\section{Bibliografia}

Bakuła B., Europa Środkowo-Wschodnia i jej (post)kolonialny świat i Studia postkolonialne w Europie Środkowej oraz Wschodniej. Kwerenda wybranych problemów (1991-2014), [w:] Dyskurs postkolonialny we współczesnej literaturze i kulturze Europy Środkowo-Wschodniej, red. B. Bakuła, Bonami, Poznań 2015, s. 13-181.

Bereśnicki L., Tłumaczę to, co wartościowe. Z Walentyną Mikołajczyk-Trzcińską, tłumaczką prozy rosyjskiej rozmawia Leszek Bereśnicki, „Sprawy Nauki” 29.07.2011, http://www.sprawynauki.edu.pl/ index.php?option $=$ com_content\&view $=$ article\&id $=1906 \&$ catid $=316 \&$ Itemid $=27$.

Bucker P., Introduction, [w:] Dictionary of Literary Biography, t. 329. Nobel Prize Laureates in Literature, part 1. Agnon-Eucken, Gale Group, Detroit 2007, s. XVIII-XIX.

Bukowski P., Heydel M., Współczesne teorie przekładu. Antologia, Wydawnictwo Znak, Kraków 2009.

Głowacka M. et al., Nagroda Nobla jako symbol globalnych norm i idei społecznych, Wydawnictwo Uniwersytetu Wrocławskiego, Wrocław 2016.

Hnatiuk O., Pożegnanie z imperium. Ukraińskie dyskusje o tożsamości, Wydawnictwo Uniwersytetu Marii Curie-Skłodowskiej, Lublin 2003.

Index Translationum: UNESCO Culture Sector, http://portal.unesco.org/culture/en/ev.php-URL_

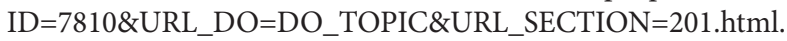

Nobelprize.org, The Official Web Site of the Nobel Prize. 2017, Facts on the Nobel Prize in Literature, http://www.nobelprize.org/nobel_prizes/facts/literature/index.html.

Riabczuk M., Od Małorosji do Ukrainy, tłum. O. Hnatiuk, K. Kotyńska, Universitas, Kraków 2002.

Riabczuk M., Ukraina: syndrom postkolonialny, tłum. zbiorowe, Kolegium Europy Wschodniej, Wrocław-Wojnowice 2015.

Robinson D., Translation and Empire, St. Jerome Publishing, Manchester 1997.

Wires R., The Politics of the Nobel Prize in Literature. A Study of Criteria behind the Choice. How Laureates Were Selected (1901-2007), Edwin Mellen Press, New York 2008.

Miscellanea Posttotalitariana Wratislaviensia 6/2017

(C) for this edition by CNS 
Антоненко П., Нобелівські лабіринти України, „Сіверщина”, 25.11.2010, http://siver.com.ua/publ/ nobelivski_labirinti_ukrajini/4-1-0-2262010.

Бубній П., Іван Франко: екскурс в нобеліану, Збірник праць ТО НТШ, t. 5. Нобелівський рух і Україна, Джура, Тернопіль 2010.

Грабович Г., До історії української літератури, Критика, Київ 2003.

Гундорова Т., Післячорнобильська бібліотека: український літературний постмодерн, Критика, Київ 2005.

Гундорова Т., Транзитна культура. Симптоми постколоніальної травми, Грані-Т, Київ 2013. Даниленко В., Лісоруб у пустелі. Письменник і літературний процес, Академвидав, Київ 2008.

Кіпіані В., Стус і Нобель. Демістифікація міфбу, „Українська Правда”, 22.07.2006, http://www. pravda.com.ua/articles/2006/07/22/3133311/.

Павлишин М., Канон та іконостас, Час, Київ 1997.

Постколоніалізм - Генераціі - Культура. Теоретичні Ревізії, випуск 4, наук. ред. А. Матусяк, Т. Гундорова, Лаурус, Київ 2014.

Струмінський Б., Мої клопоти з певною традицією в українській літературі, „Сучасність” 1986, nr 4, s. 114-116.

Шкандрій М., В обіймах імперії. Російська і українська літератури новітньої доби, Факт, Київ 2004.

Przyjęto do druku/Accepted for publication: 15.05.2017

Miscellanea Posttotalitariana Wratislaviensia 6/2017

(C) for this edition by CNS 